

\section{THIS PAPER}

--represents an effort by the Society to deliver technical data direct from the author to the reader with the greatest possible speed. To this end, it has had none of the usual editing required in more formal publication procedures.

Readers are invited to submit discussion applying to current papers. For this paper the final date on which a discussion should reach the Manager of Technical Publications appears on the front cover.

Those who are planning papers or discussions for "Proceedings" will expedite Division and Committee action measurably by first studying "Publication Procedure for Technical Papers" (Proceedings Paper No. 290). For free copies of this Paper-describing style, content, and format-address the Manager, Technical Publications, ASCE.

Reprints from this publication may be made on condition that the full title of paper, name of author, page reference, and date of publication by the Society are given.

The Society is not responsible for any statement made or opinion expressed in its publications.

This paper was published at 1745 S. State Street, Ann Arbor, Mich., by the American Society of Civil Engineers. Editorial and General Offices are at 33 West Thirty-ninth Street, New York 18, N. Y. 


\title{
FLOW INTO A WELL BY ELECTRIC AND MEMBRANE ANALOGY
}

\author{
Chong-Hung Zee, ${ }^{1}$ Dean F. Peterson, M. ASCE, ${ }^{2}$ \\ and Robert O. Bock ${ }^{3}$
}

\section{SYNOPSIS}

A study of radially symmetrical, unconfined flow to a well is reported. Discharge of such a system is related, using dimensional considerations, to the permeability of the aquifer and the geometric characteristics of the influence region. The authors combine the electrical analogy for hydraulic flow with the membrane analogy for the free surface in order to study the problem. Their experimental results are combined with observations of other investigators to obtain empirical relationships between the flow and the geometric variables.

\section{NOTATION}

The letter symbols adopted for use in this paper are defined where they first appear, in the illustrations or in the text, and are arranged alphabetically for reference in the Appendix.

\section{INTRODUCTION}

Most drainage wells, and a great many water supply wells, tap aquifers whose upper boundaries are not defined by impermeable strata. Solutions for the flow pattern under steady conditions, even for mathematically ideal wells of this class, are difficult because the location of the upper limiting boundary of the flow cross-section is not known. Furthermore, the geometry of the flow system outside of the well may not be deterinined knowing only the drawdown and the geometry of the well. Either both the well discharge and the permeability, or else the elevation of the free water surface at a known radial distance from the well, must also be known. A further complicating factor results from hydrodynamic considerations, which require that the water surface stand at a higher elevation outside of the well casing than inside, even though hydraulic head losses through the casing are zero. Under certain conditions, this difference of elevation, called the seepage face, may be considerable. It is an important consideration where drainage wells are intended to produce maximum lowering of a water table.

An early solution for the fully penetrating well in an unconfined aquifer was proposed by Dupuit in 1863, Eq. 1.

1. Structural Designer, Ammann and Whitney, Cons. Engs., New York, N. Y.

2. Prof. and Head, Dept. of Civ. Eng., Colorado A and M College, Fort Collins, Colo.

3. Senior Eng., Arma Corp., Garden City, N. Y 


$$
h^{2}-h_{w}^{2}=\frac{Q}{\pi K} \ln \frac{r}{r_{w}}
$$

In Eq. 1, h is the vertical distance from the bottom impermeable stratum to the free water surface at radial distance $r$ from the well axis, $h_{w}$ is the depth of water in the well, $r_{w}$ is the well radius, $K$ is the permeability of the aquifer and $Q$ is the discharge of the well. Dupuit's solution ignored the effect of curvilinear flow in a vertical plane. Investigators have found that Eq. 1 predicts the discharge correctly if $\mathrm{r}$ is chosen sufficiently far from the well; it does not describe the true position of the water surface near the well, however.

Most recent attempts to solve this flow problem have been by means of models and analogues. Wyckoff, Botset and Muskat (8) in 1932 made an investigation using a 15-degree sector sand model. Owing to capillarity, the position of the free surface near the well was not fully determined. In 1948, Babbitt and Caldwell(1) made similar studies using a sand wedge. A carbon wedge electrical analogue was also used by these investigators, who suggested an empirical equation for the free surface. Hansen, $(3)$ in 1949 , proposed that a depressed membrane under tension be used to simulate the free surface. He also proposed a functional expression, Eq. 2.

$$
\frac{Q}{K r_{w}^{2}}=f\left(\frac{h_{s}}{r_{w}}, \frac{h_{w}}{r_{w}}\right)
$$

relating the depths of water outside and inside of the well to the radius of the well, the discharge, and the permeability of the aquifer. In Eq. $2, \mathrm{~h}_{\mathrm{S}}$ is the depth of the water immediately outside of the well.

Numerical analysis, using relaxation methods, was applied to six cases of unconfined radial flow by Yang ${ }^{(9)}$ in 1949.

During 1950 and 1951, the authors conducted experiments on this problem. They combined the electrical analogy for flow with the membrane analogy for a free surface. Using this method, a relatively large number of cases was studied quite easily. Information from these experiments was combined with that from other sources and from one field test. This was used to develop empirical curves showing the general relationships between geometric and flow variables expressed in dimensionless form.

\section{Theory}

Seepage flow in cylindrical co-ordinates

Substitution of Darcy's equation for flow in a saturated, isotropic, pervious medium into the differential equation of continuity for flow of an incompressible fluid leads to Laplace's equation for steady seepage flow. In cylindrical co-ordinates this is expressed by Eq. 3 .

$$
\frac{\partial^{2} h}{\partial r^{2}}+\frac{1}{r} \frac{\partial h}{\partial r}+\frac{1}{r^{2}} \frac{\partial^{2} h}{\partial \theta^{2}}+\frac{\partial^{2} h}{\partial z^{2}}
$$


In Eq. 3, $\mathrm{h}$ is the piezmetric head at a point having the co-ordinates $\mathrm{z}, \mathrm{r}$ and $\boldsymbol{\theta}$. Boundary conditions for the idealized case of unconfined flow toward a central, fully penetrating well are shown by Fig. 1. The pervious medium,

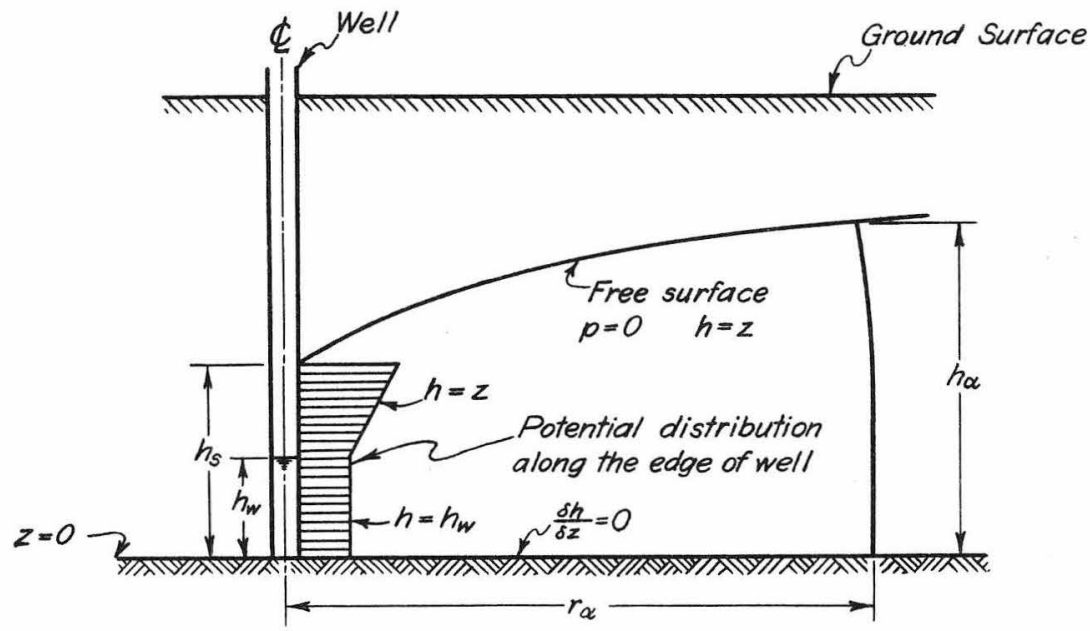

Fig. I Boundary Conditions for the Idealized Well

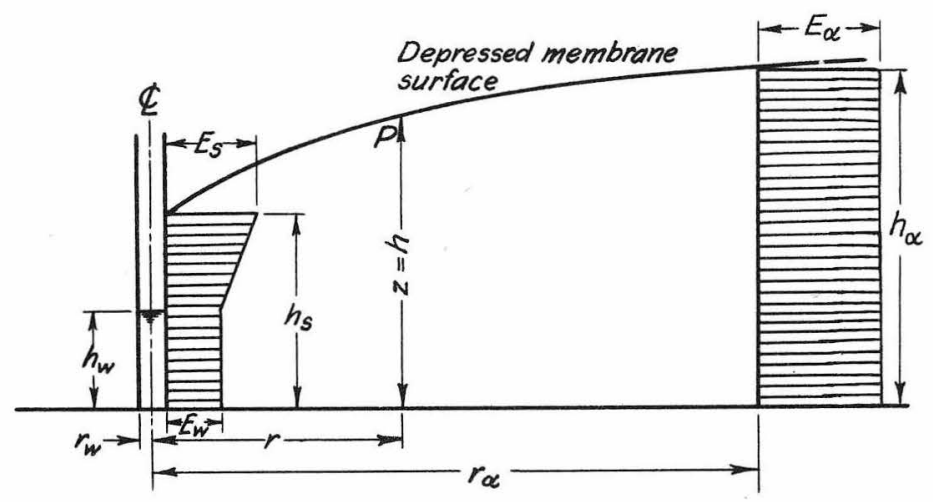

Fig. 2 Boundary Conditions for the Electrical Model

bounded by the impermeable stratum, is assumed to extend indefinitely in a radial direction. At the well, the outflow surface below the level of the drawdown is an isopotential surface on which the head $h_{w}$ is measured from the elevation of the bottom of the well. Above this elevation, along the seepage face and the free water surface extending back from the well, the gage pressure is zero. The piezometric head along these boundaries must therefore be $z$. 
An isopotential surface at some finite $r$ may be chosen as the inflow boundary for a finite system. To correspond to the indefinitely extending system, this boundary should be slightly curved in a vertical plane as indicated by Fig. 1. The curvature decreases as $r$ increases.

Some interesting mathematical considerations arise in connection with the boundary conditions near the well. For example, the necessity that a real seepage face exist may be inferred as follows. ${ }^{2}$ Consideration of the properties of an interface between two fluids existing in media having different permeabilities leads to the conclusion that the free surface, or top streamline, must approach the well tangentially with a velocity of $\mathrm{K}$. Below the elevation of the water surface in the well, the streamlines intersect the well boundary normally because this is an isopotential surface. If one assumes that the top streamline intersects the water surface of the well, the resulting convergence of the streamlines near the elevation of the water in the well would imply infinite velocity rather than $\mathrm{K}$, as required. Also, if one assumes the drawdown to be zero, non-existence of the seepage face would result in zero discharge area and infinite velocity through the well boundary. Actually, the direction of approach of the streamlines changes throughout the length of the seepage face from tangential at the top of the seepage face to normal at the elevation of the water surface in the well. Theoretically, the exit velocity into the air along the seepage face is proportional to $\operatorname{cosecant} \beta$, where $\beta$ is the angle of inclination of the streamline at the point of egress. This consideration again leads to postulation of infinite velocity at the elevation of the water in the well. Actually, in this vicinity, the velocity probably exceeds that for which Darcy's equation is valid and thus approaches some finite maximum. The function, $h(z)$, on the well boundary is not analytic at a point at the elevation of the water surface in the well. Below this point, $\mathrm{h}(\mathrm{z})=\mathrm{h}_{\mathrm{W}}$ and above, $\mathrm{h}(\mathrm{z})=\mathrm{z}$.

\section{Electrical analogy}

The electrical analogy is based on the similarity of Darcy's equation to Ohm's law.

In the analogue, electromotive potential $\mathrm{E}$ corresponds to head $\mathrm{h}$ and current $I$, to hydraulic discharge $Q$. The analogue must be geometrically similar to the well and surrounding region. In addition, the voltage variation on any free surface must be linear in a vertical direction to correspond to gravity head. This condition is expressed by Eq. 4,

$$
E_{1}-E_{2}=S\left(z_{1}-z_{2}\right)
$$

where $E_{1}$ and $E_{2}$ are voltages at points in the free surface or seepage face having the vertical co-ordinates $z_{1}$ and $z_{2}$. The model constant $S$ equals the electromotive potential gradient in a vertical direction on any free surface in the model and thus corresponds to the gradient of gravity in the prototype, which is unity. The constant $S$ may best be introduced by considering the permeability $\mathrm{K}$ as analogous to $\mathrm{S} \sigma$ where $\sigma$ is the specific conductivity of the electrolyte.

\section{Membrane analogy}

The membrane analogy is based on the equation for deflection of a membrane under uniform tension clamped to a circular ring at the periphery and deflected by a small cylindrical rod at the center. The deflection, $y$, is approximated by the equation, 


$$
\frac{d^{2} y}{d r^{2}}+\frac{1}{r} \frac{d y}{d r}+\frac{r t}{T}=0
$$

In Eq. 5, $\mathrm{T}$ is the tension, $\mathrm{t}$ is the membrane thickness and $\gamma$, the specific weight of the membrane. When $\mathrm{T}$ is large in comparison with $\gamma_{\mathrm{t}}$, the term $\gamma_{t} / \mathrm{T}$ in Eq. 5 becomes very small.

For axially symmetrical flow, Eq. 3 reduces to

$$
\frac{\partial^{2} h}{\partial r^{2}}+\frac{1}{r} \frac{\partial h}{\partial r}+\frac{\partial^{2} h}{\partial z^{2}}=0
$$

On the free surface, $\mathrm{h}$ is equal to $\mathrm{y}$ (except for a difference in datum) and can be expected to satisfy Eq. 5 except for the differences in the small non-homogeneous term. Accepting this approximation, the membrane analogy may be used to study seepage flow.

\section{Dimensional analysis}

Eq. 2 is a special case of a more general expression. The variables $Q$, $\mathrm{K}, \mathrm{r}_{\mathrm{W}}, \mathrm{h}_{\mathrm{w}}, \mathrm{r}$ and $\mathrm{h}$, where $\mathrm{h}$ is the known depth of water at a radial distance $r$, should be sufficient to define a particular system of flow. These variables may be arranged to form

$$
\frac{Q}{K r_{w}^{2}}=f_{2}\left(\frac{h_{w}}{r_{w}}, \frac{h}{r_{w}}, \frac{r}{r_{w}}\right)
$$

By choosing $r=r_{W}$, h becomes $h_{S}$ and Eq. 2 may be deduced from Eq. 7 . Further, one might have chosen $h_{S}$ in place of $h_{W}$ as a pertinent variable to form,

$$
\frac{Q}{K r_{w}^{2}}=f_{3}\left(\frac{h_{s}}{r_{w}}, \frac{h}{r_{w}}, \frac{r}{r_{w}}\right)
$$

Knowledge of the values of water depth, $h_{1}$ and $h_{2}$, at two radial distances, $r_{1}$ and $r_{2}$, should be sufficient to establish the corresponding free surface profile for a well of a particular radius $r_{\mathrm{w}}$. Arranging this postulate in dimensionless expression yields Eq. 9.

$$
f_{4}\left(\frac{h_{1}}{r_{w}}, \frac{h_{2}}{r_{w}}, \frac{r_{1}}{r_{w}}, \frac{r_{2}}{r_{w}}, \frac{h}{r_{w}}, \frac{r}{r_{w}}\right)=0
$$

A single value of $\frac{\mathrm{Q}}{\mathrm{Kr}_{\mathrm{w}}{ }^{2}}$ is associated with each dimensionless free surface profile resulting from a particular solution of Eq. 9.

\section{Laboratory Investigations}

\section{Apparatus}

The basic apparatus used by the authors consisted of an open-topped cylindrical tank, a rubber membrane assembly, and a simulated well. A 
cylindrical tank being used, the inflow boundary as shown by Fig. 1 cannot be duplicated exactly. Actual boundary conditions obtainable with the model are shown by Fig. 2. They differ from those of Fig. 1 only at the inflow boundary -a difference which becomes negligible for fairly large values of $r$.

A drawing of the model is shown by Fig. 3. The wall of the tank was of
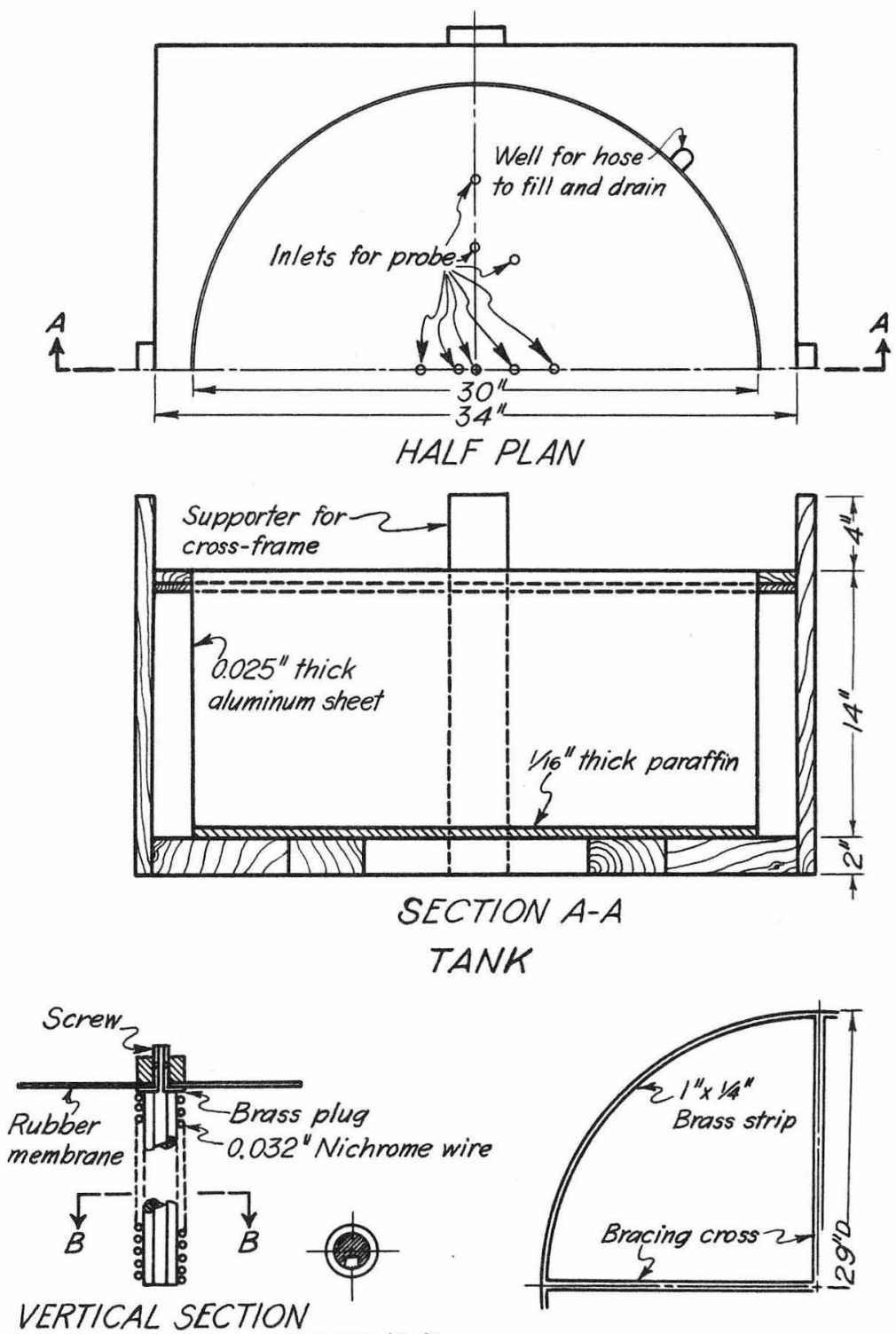

\section{WELL}


aluminum sheet and the floor was of plywood waterproofed with paraffin. Fig. 4 is a view of the empty tank. The membrane, which consisted of ordinary nursery rubber sheeting, was mounted on a ring fabricated of brass strip. It was clamped to the ring with a tension bank cushioned with strip rubber, Fig. 5. The membrane assembly was supported by four threaded hangers

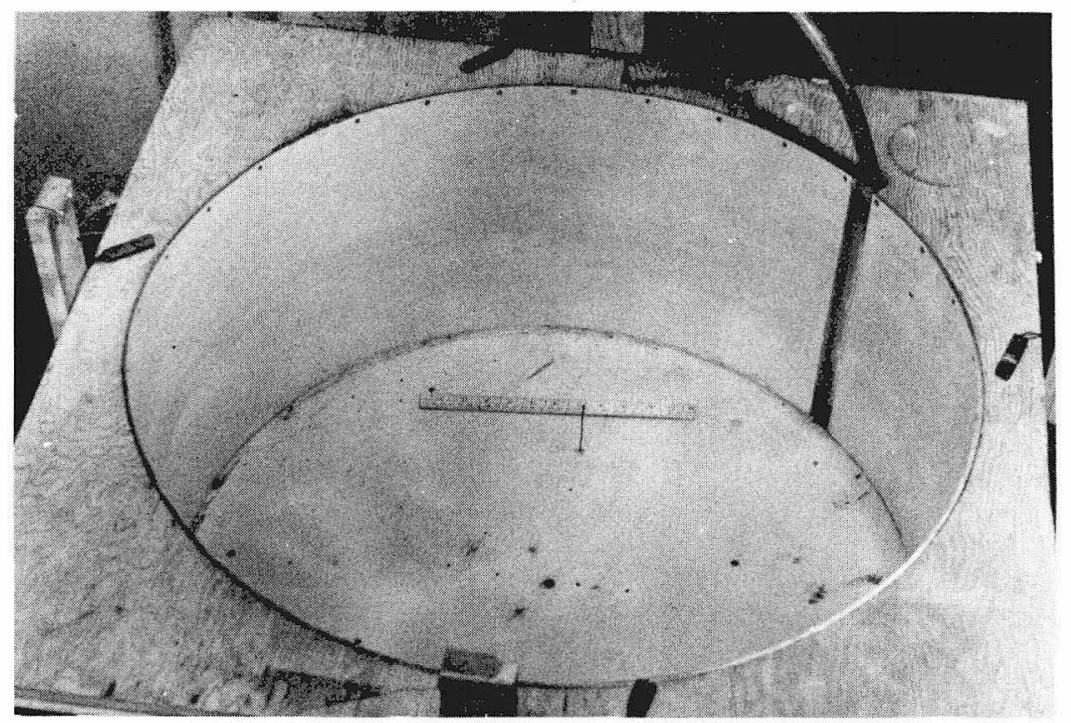

Fig. 4 Tank for Electrical Model

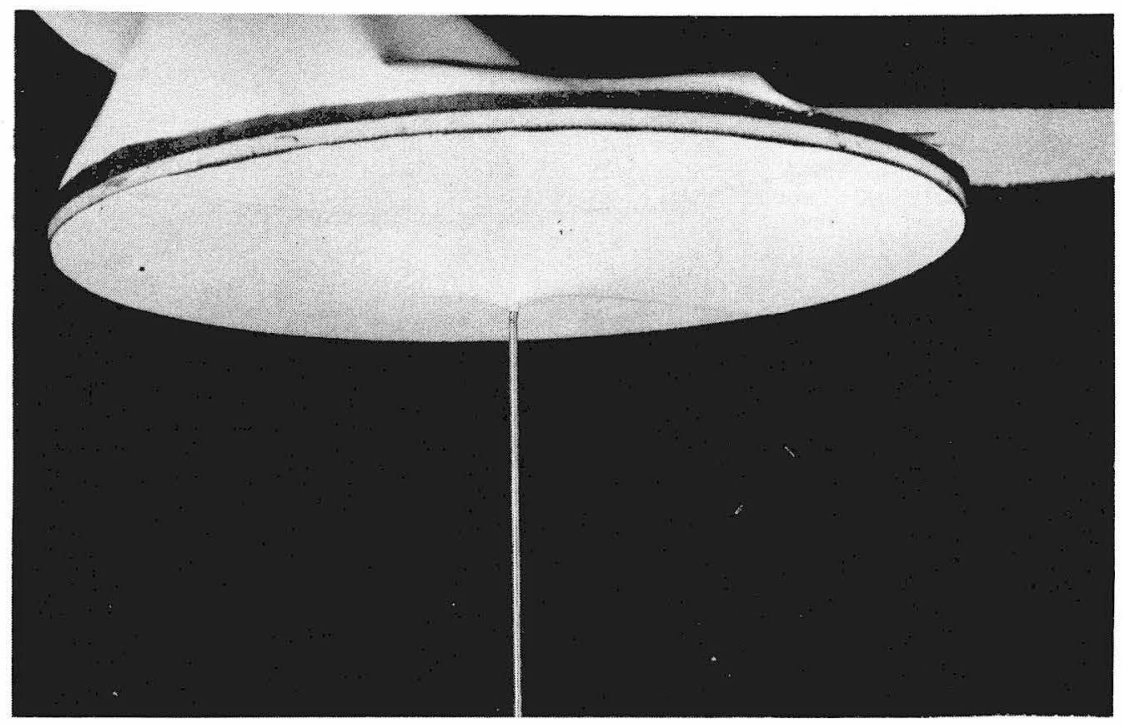

Fig. 5 Rubber Membrane Mounted on Ring 
from a cross frame mounted over the tank. The ring and membrane could thus be raised and lowered to provide different values of $h_{\alpha}$, the depth of water at the inflow boundary. The thickness of the membrane was $0.12 \mathrm{in}$. and its specific gravity was 1.45. A tensile stress of 70 grams per centimeter produced a unit strain of 0.2 in the membrane material. In order that there exists no difference of pressure between the two sides of the depressed membrane, the electrolyte was placed on both sides as shown by Fig. 6 . Along the circumference of the ring, the spare portion of rubber sheet was raised so that current from the tank shell could not flow through the solution above the membrane. The surface profile of the depressed membrane was measured using the point gage rule shown in $\mathrm{Fig} .6$.

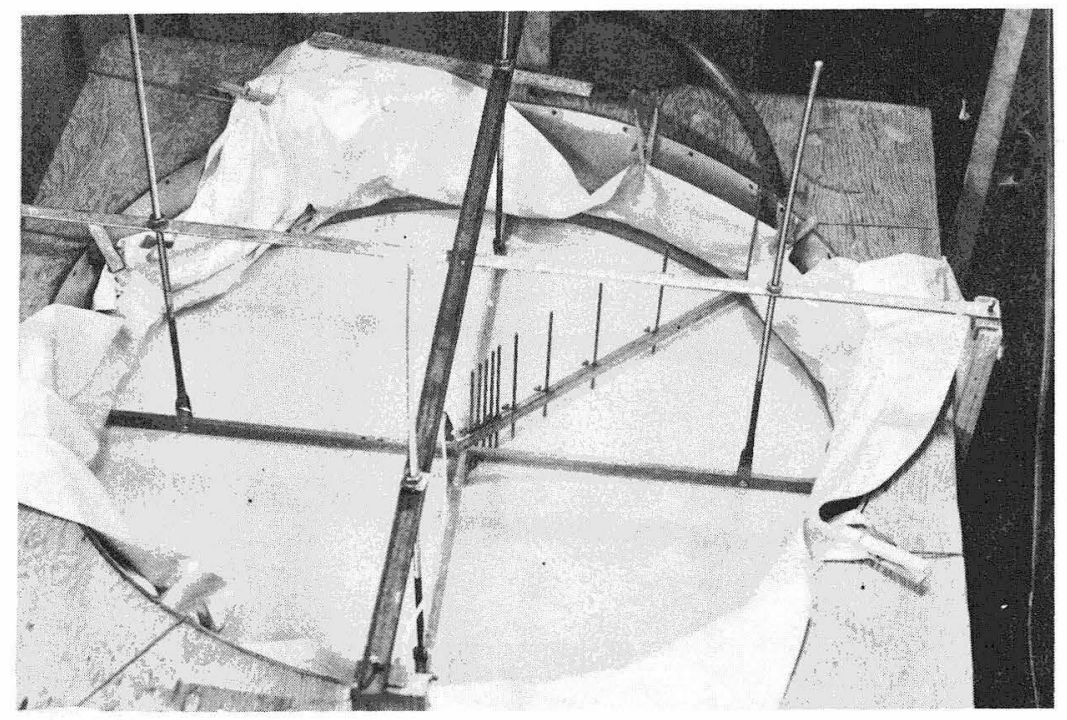

Fig. 6 Electrical Model Assembly during Test
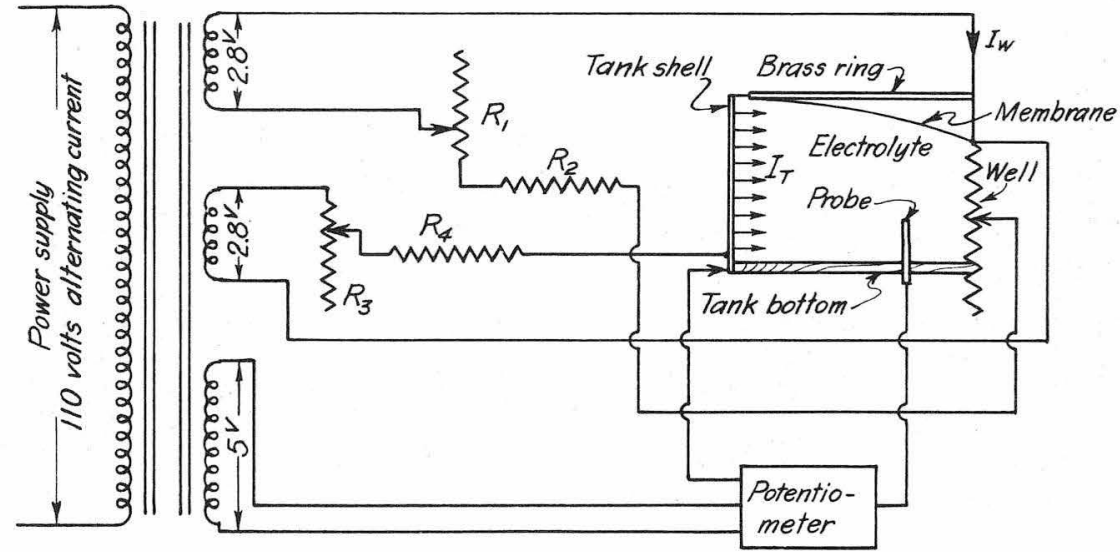

Fig. 7 Electrical Circuits for the Model 
The well was fabricated of $1 / 4 \mathrm{in}$. diameter plastic rod on which was wound a helix of nichrome wire (diameter 0.032 in., resistance 0.0193 $\mathrm{Ohms} / \mathrm{cm}$ ). The wire was seated in $1 / 4 \mathrm{in} .28$ threads, giving a clearance between adjacent turns of the wire of .0037 in. This arrangement made possible uniform potential drop along the length of the rod. Prior to winding, a $3 / 32$ in. slot was milled lengthwise in the rod. A $3 / 32$ in. brass tube was placed in the slot. This tube could slide in the slot to a height representing the water level in the well. By thus shorting across the winding, the constant potential section of the model well was provided.

The effective radius of the well model could not be determined by direct measurement because of the uncertainty regarding the electrical boundary of the wire helix. The following indirect method was accordingly used. The entire length of the well was maintained at constant potential and a radially symmetrical, polar, potential field imposed in the surrounding electrolyte. Such a field has logarithmic distribution radially. By measuring the potential along a radius, this distribution was obtained and the results extrapolated to correspond to a radius having the same potential as the well. This is the effective radius. For the model well it was found to be $0.314 \mathrm{~cm}$.

Electrical circuits are shown in Fig. 7. Alternating current was used to minimize polarization. Two power sources were necessary. One source provided the current $I_{W}$ to maintain the required potential distribution along the well. The same value of $I_{w}$ was used for all of the tests and this was maintained by adjusting the resistance $R_{1}$. The other source provided the current $I_{T}$ which passed through the electrolyte and was analogous to the hydraulic discharge. The potential drop between any two points was measured using a potentiometer connected to an oscillograph through a pre-amplifier. Values of $I_{W}$ and $I_{T}$ were calculated from measurements of potential drop across the resistances $R_{2}$ and $R_{4}$, respectively. A water solution of 0.2 per cent acetic acid was used for the electrolyte. Following each run the conductivity of the electrolyte was measured using a cell especially constructed of plastic.

The potential field in the electrolyte was surveyed using a probe inserted through holes in the bottom of the tank. This probe was constructed of straight glass tubing of $3 / 32$ in. diameter through which a 17 gage copper wire had been threaded. This probing end was sealed with paraffin. Eight holes for the probe were arranged radially and fitted with copper seal caps to prevent leakage.

\section{Test runs}

Equations 7 and 8 imply that single values of $\mathrm{Q} / \mathrm{Kr}_{\mathrm{w}}{ }^{2}$ and $\mathrm{h}_{\mathrm{w}}$ are associated with each particular set of values of $h_{\alpha}, r_{\alpha}, h_{S}$ and $r_{w}$. Selection of such a set for a single test run fixed the geometric configuration of the model. Further, selection of $h_{\alpha}$ and $h_{S}$ determined the value $E_{\alpha}-E_{s}$. The values of $\mathrm{h}_{\mathrm{w}}$ and its associated $\mathrm{E}_{\mathrm{w}}$ were found by trial. To accomplish this, the sliding tube in the analogous well was adjusted until Eq. 4 was satisfied by measured values of potential along the membrane boundary and at the analogous water surface in the well.

The value of $r_{\alpha}$ was fixed by the size of the tank. Since the effective diameter of the well did not change, the value of $r_{\alpha} / r_{w}$ was 115 for all runs. A total of 28 test runs were made.

\section{Mosca Test Well}

During March, 1954 an experimental well located near Mosca, Colorado 
was tested by Mr. W. E. Code of the Colorado Experiment Station and Mr. Peterson. Natural conditions at this site are such that they correspond closely with the ideal conditions imposed on the laboratory experiments. The shallow topsoil is underlain by extensive water-bearing gravel and sand and there is no upper confining stratum. The water table is practically level. The log for the well is as follows:

$$
\begin{aligned}
& \text { Depth } \\
0 & -3 \text { Ft } \\
3 & -25 \\
25 & -45 \\
45 & -57
\end{aligned}
$$

\section{Material}

Topsoil

Sand and gravel, clay lenses Brown sandy clay

Blue clay

The hole was drilled $24 \mathrm{in}$. in diameter to a depth of $57 \mathrm{ft}$. using cable tools. A 24 in. blank casing was placed to a depth of $35 \mathrm{ft}$. and the hole backfilled with gravel to a depth of $29 \mathrm{ft}$. below ground surface. An 18-in. well casing was set and the blank casing withdrawn. The ground elevation at the well was taken as $+94.0 \mathrm{ft}$. Six observation wells were located on a radial line north of the pumped well at distances ranging from 6.0 to $600.0 \mathrm{ft}$. Other observation wells were located $112.0 \mathrm{ft}$. west, $133.0 \mathrm{ft}$. south and $136.5 \mathrm{ft}$. east.

Fig. 8 shows the elevation of the water in the observation wells initially, and after 64.6 hours of continuous pumping. The initial level condition of the water surface is indicated. After pumping, the water surface elevation at the east, south and west wells agreed closely with the drawdown curve for the north radius, indicating good radial symmetry.

After 64.4 hours of pumping, the discharge was $0.364 \mathrm{cfs}$. Application of Dupuit's equation gave $K=2.23 \times 10^{-3} \mathrm{ft} / \mathrm{sec}$. Theis's equation (11:321), applied during the depletion period, gave $\mathrm{K}=2.28 \times 10^{-3} \mathrm{ft} / \mathrm{sec}$. The initial depth of water in the well, $h_{\alpha}$, was $22.0 \mathrm{ft}$. The depth $h_{w}$ of water in the well after 64.6 hours of pumping was $10.0 \mathrm{ft}$. and the depth $h_{\mathrm{s}}$ outside of the casing was determined, by extrapolating the drawdown curve of Fig. 8, as $12.8 \mathrm{ft}$. The effective radius $r_{\mathrm{w}}$ of the well, determined as indicated in the discussion section of this paper, was $0.72 \mathrm{ft}$.

\section{Presentation and Discussion of Results}

\section{Free surface profiles}

In order to reduce observed free surface profiles to a single set of comparable curves, standard values of $r_{1}$ and $r_{2}$ need to be chosen in Eq. 9. For this presentation, $r_{1}$ was chosen as $r_{w}$ and $r_{2}$ as $115 r_{w}$. The corresponding value of $h_{1}$ is $h_{w}$ and $h_{2}$ is designated $h_{115}$. The value of $115 r_{w}$ was arbitrarily chosen to correspond to the dimensions of the tank used by the authors. Choosing the elevation of $\mathrm{h}_{115}$ as datum, Eq. 9 may be rewritten in the form,

$$
f_{5}\left(\frac{h_{115}-h_{s}}{r_{w}}, \frac{h_{115}-h}{r_{w}}, \frac{r}{r_{w}}\right)=0
$$

Available data from all sources were arranged in the form of Eq. 10 and plotted. Where the data were otherwise adequate but did not extend to radial distances of $115 \mathrm{r}_{\mathrm{w}}$, they were extrapolated using Dupuit's equation. After careful consideration, best fit curves were drawn. These are shown by Fig. 9. For simplicity, only the data taken by the authors, including the Mosca 


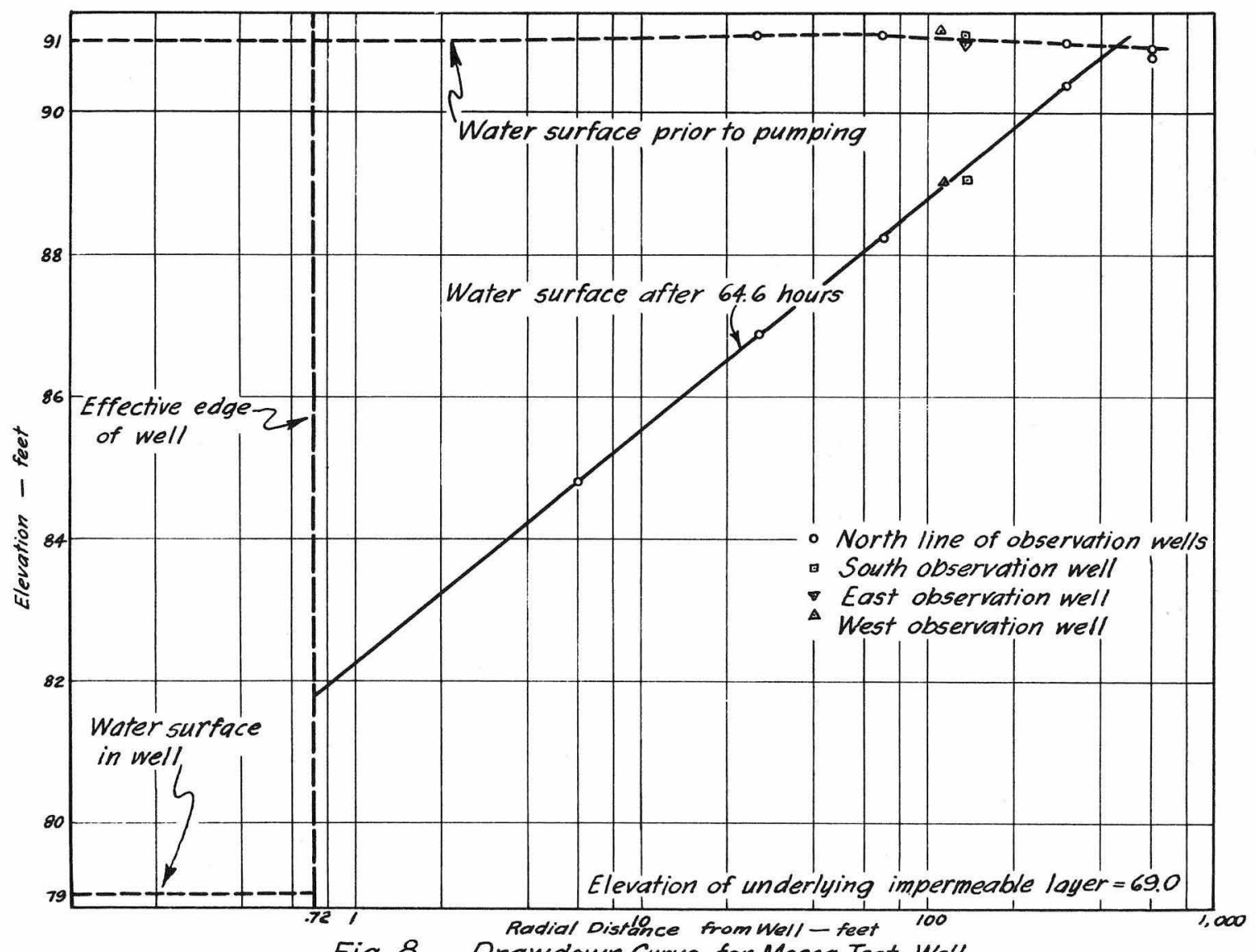

Fig. 8 Drawdown Curve for Mosca Test Well 


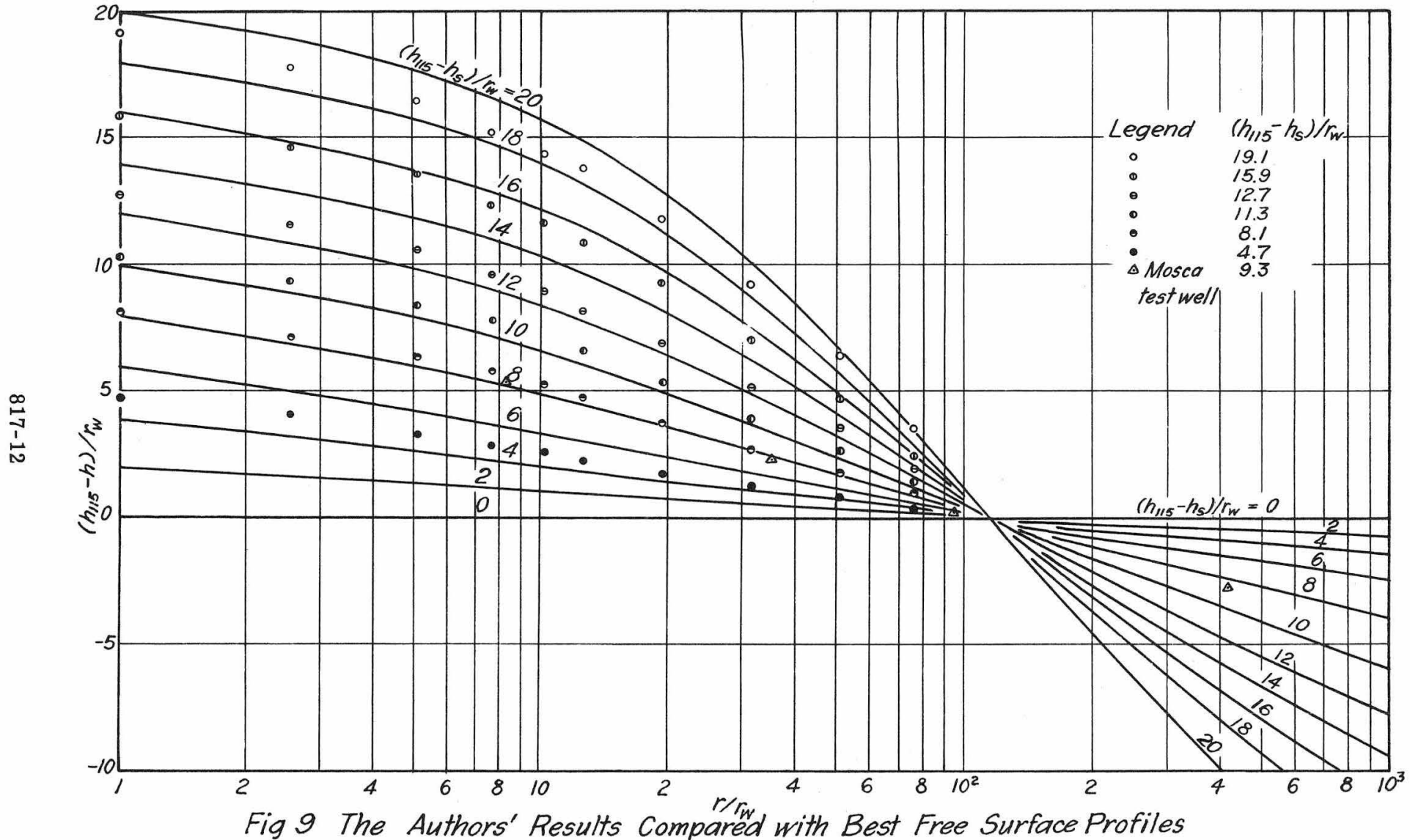




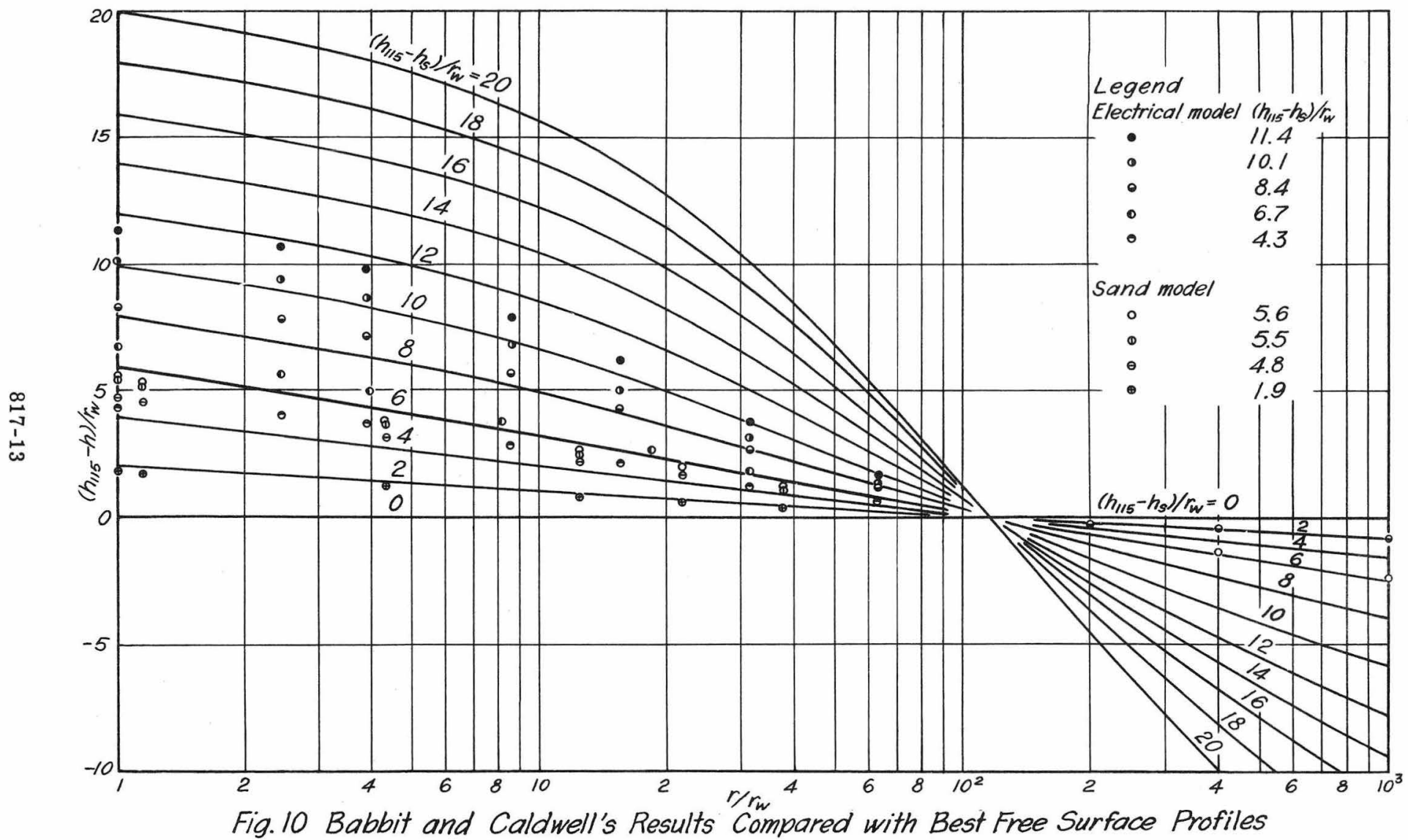




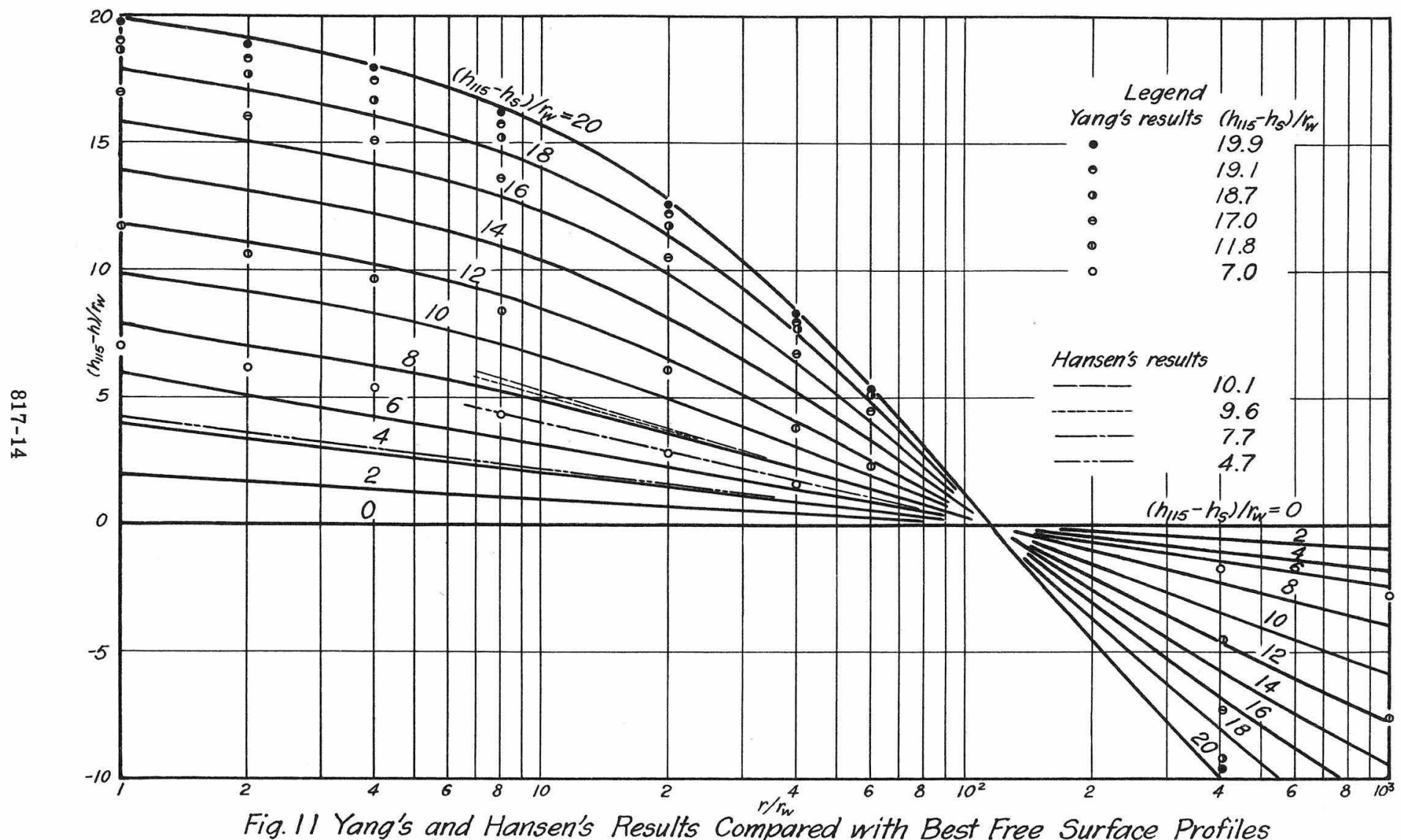


Test Well data, are shown on this figure. The data of Babbitt and Caldwell are shown on Fig. 10 and those of Yang and Hansen, on Fig. 11. The plotted curves are the same for all three figures.

Reference to the figures shows good correlation of the data from the various sources. The membrane profile agrees very well with profiles obtained by other investigators and with the field test information. While the membrane analogy is not exact, owing to the difference in the non-homogeneous terms of Eqs. 5 and 6, the results indicate that the descrepancy introduced by this difference cannot be large for the range of variables covered by this investigation. The data of Yang and Hansen indicate that the free surface profile near the well is not a linear logarithmic function of the radial distance for cases where the drawdown is large.

The curves of Fig. 9 may be used to predict the free surface profile for a well if $h_{115}$ and the depth at some other radius are known. By combining the use of these curves with those of Fig. 12, the free surface profiles may also be predicted if discharge and permeability and either $h_{w}, h_{S}$, or $h_{115}$ are known.

\section{Discharge data}

Discharge was first studied in its relationship to the geometric variables at the well, that is, in relation to $r_{w}, h_{w}$ and $h_{s}$; and to permeability $K$. For this purpose, the variables were arranged in the form of Eq. 2. Data from all sources were plotted as shown on Fig. 12. Curves showing the variation of $h_{S} / r_{w}$ and $Q / K^{w}{ }^{2}$ for various values of $h_{w} / r_{w}$ were drawn. These are the solid lines.

Measurement of $h_{S}$ is difficult, both in the laboratory and in the field, because of the rapidly changing water surface elevation near the well, the ef fect of capillarity in sand models, and for possibly other reasons. The discharge information would have more general use if it were presented in terms of a water depth measured at some distance from the well, an observation that can be made with considerable confidence. For this purpose, $\mathrm{h}_{\mathrm{w}} / \mathrm{r}_{\mathrm{w}}$ in Eq. 2 was replaced by $\mathrm{h}_{115} / \mathrm{r}_{\mathrm{w}}$. Corresponding values of the latter variable are indicated in parentheses on Fig. 12 for each datum previously plotted. Curves showing variation of $\mathrm{h}_{\mathrm{S}} / \mathrm{r}_{\mathrm{W}}$ are drawn in dashed-line legend.

Generally data from all sources correlate very well on Fig. 12. Those obtained using the electric-membrane analogy agree closely with values obtained from other experiments, numerical solution of Eq. 6, and the field test. Advantages of the electric-membrane analogy combination are fairly obvious. A large amount of information may be obtained rapidly and inexpensively. Capillary effects, often very appreciable in sand models, are eliminated. The water depth $\mathrm{h}_{\mathrm{s}}$ immediately outside the well casing is directly and readily measured.

Knowledge of any two of the variables $Q / \mathrm{Kr}_{\mathrm{w}}^{2}, \mathrm{~h}_{\mathrm{S}} / \mathrm{r}_{\mathrm{w}}, \mathrm{h}_{\mathrm{w}} / \mathrm{r}_{\mathrm{w}}$ and $\mathrm{h}_{115} / \mathrm{r}_{\mathrm{w}}$ makes possible prediction of the other two from Fig. 12. For instance, if the discharge parameter $\mathrm{Q} / \mathrm{Kr}_{\mathrm{W}}^{2}$ and either $\mathrm{h}_{\mathrm{W}} / \mathrm{r}_{\mathrm{W}}, \mathrm{h}_{\mathrm{S}} / \mathrm{r}_{\mathrm{W}}$ or $\mathrm{h}_{115} / \mathrm{r}_{\mathrm{W}}$ are known, the other geometric variables may be predicted. Using these, Fig. 9 may be entered to predict the entire free surface profile. Further uses of Fig. 12 include predicting discharge from drawdown and permeability information and predicting the height of the seepage face.

\section{Potential distribution}

Distribution of potential in a radial plane was determined for several of the test runs made by the authors. An example of one of these is shown by Fig. 13. The flow net was drawn from observations of potential made using 


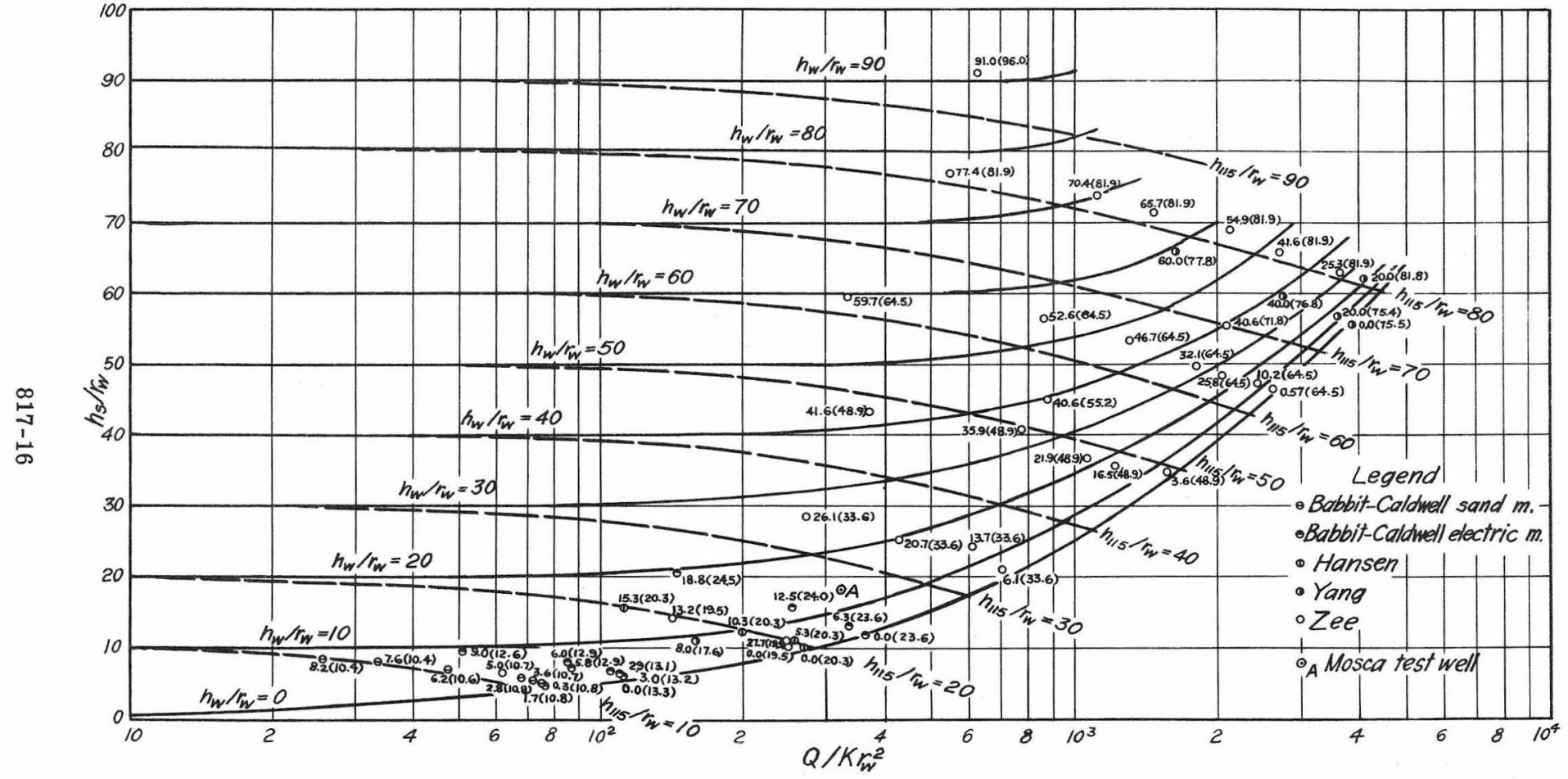

Fig. 12 Relationship of Discharge and Geometric Parameters 
Test No.l

$h_{115} / r_{w}=48.9$

$h_{s} / r_{w}=36.9$

$h_{w} / r_{w}=21.9$
Values in parentheses are the

corresponding values computed by equation(7)

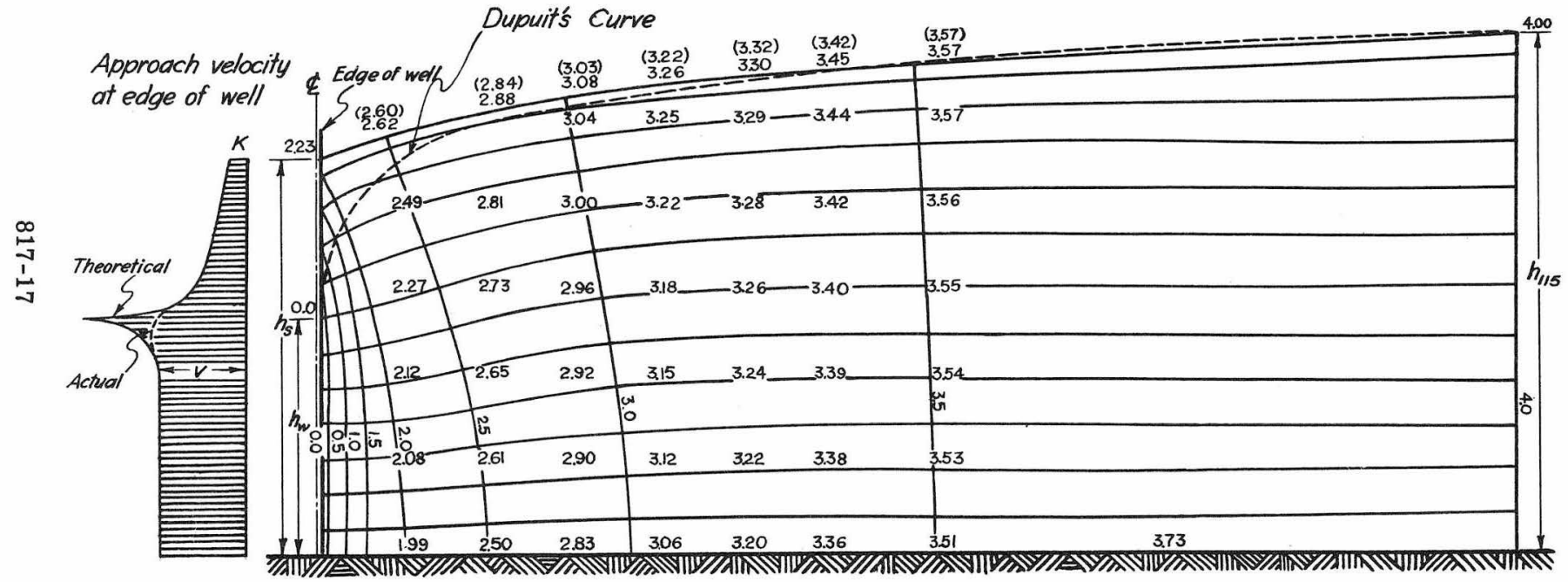

Fig.13 Radial Flow Pattern for a Gravity Well 
expressed by Eq. 4. The numbers in parentheses on Fig. 13 were computed using observed values of $\mathrm{z}$ for the membrane. These may be compared with the observed values of potential to demonstrate the degree to which the depressed membrane actually satisfied the gravity criterion.

The velocity of the water approaching the seepage face was computed from the equation $\mathrm{V}=\mathrm{K}$ cosecant $\beta$ using values of $\beta$ obtained from the flow net. A curve showing the computed velocity distribution at the edge of the well is included in Fig. 13. This curve is based on the assumption that the well boundary below elevation $h_{\mathrm{W}}$ remains an isopotential surface. Actually, the axial acceleration of the inflowing water along the length of the well screen modifies uniform potential distribution along the length of the actual well. $\left.{ }^{6}\right)$ Fig. 13, at least theoretically, gives guidance to placing the well screen most economically insofar as best hydraulic performance is concerned.

Also shown on Fig. 13 is the location of the free water surface as computed using the Dupuit equation. While deviations are large near the well, agreement is good at fairly large distances. The Dupuit equation has been used for determination of permeability using pumping tests. Fig. 13 may be used to give an indication of the distance from the well at which reasonably accurate results might be expected.

\section{Effective radius}

For a developed well or a well with gravel envelope, the effective radius may be substantially different from the actual radius of the well screen. In 1947 , Jacob ${ }^{(4)}$ discussed this problem and proposed methods for determining the effective radius of an artesian well. By trial and error, Fig. 12 may be used to determine the effective radius of a steady-state well in an unconfined aquifer. If $Q, K$ (from a pump test), $h_{W}$, and $h_{115}$ are known, a trial value of $r_{W}$ is assumed and $Q / K_{W}{ }^{2}, h_{115} / r_{W}$, and $h_{W} / r_{W}$ are computed and plotted on Fig. 12. If $r_{w}$ has been correctly assumed, this point will correspond with the curves of Fig. 12. If not, a new value of $r_{w}$ is assumed and the procedure repeated until substantial agreement is reached.

\section{SUMMARY}

Even for the idealized case of a fully-penetrating, steady-state well in an unconfined aquifer, exact mathematical expressions relating the geometric and flow variables have not been found. Much empirical information has been collected by many investigators, however. Some of this has been obtained from field tests, but most systematic investigations have been made using sand models or electrical analogues employing carbon wedges. Use of sand models is cumbersome and capillary effects are large. Using carbon wedges, the free surface must be carved to a radial profile located by trial and error. Numerical solution of the boundary value problems for six specific cases has also been accomplished, but the task is tedious owing to the radial convergence of flow.

To facilitate systematic interpretation of empirical information, dimensional considerations were used to arrange the variables in postulated functional expressions. These postulates are stated as Eqs. 7, 8, 9 and 10. In order to obtain adequate data rapidly and with minimum effort, the authors used apparatus which combined the electrical analogue for flow with the membrane analogy for the free surface. Using this apparatus, data for a number of simulated cases were readily obtained. Data from one field test of a well under the rather idealized conditions of the problem were also collected. 
The results are presented in three forms: (1) geometric relationships of the dynamic system, (2) relationships between flow variables and geometric variables, and (3) potential and flow distribution patterns. Geometric relationships are presented in Fig. 9 as a single family of water surface profile curves. The curves of this figure are based on data from all available sources. Empirical data of the authors are also shown on this figure for comparison with these curves. Fig. 12 shows the relationship between the flow variables of discharge and permeability with well radius $r_{w}$, depth of water in the well $h_{\mathrm{w}}$, depth outside the casing $\mathrm{h}_{\mathrm{S}}$, and depth at a distance of 115 well radii $h_{115}$. The curves of Figs. 9 and 12 may be used to predict values of the unknown variables if certain of the other variables are known. Of particular interest is the magnitude of the seepage face at the well boundary, which may be computed as the difference of $h_{s}$ and $h_{w^{*}}$ Fig. 13 is a typical example of a radial flow net for a specific case investigated by the authors. Also shown by Fig. 13 is the velocity distribution at the boundary of the well for the specific case considered.

\section{ACKNOWLEDGMENTS}

The experimental work leading to this paper was conducted by $\mathrm{Mr}$. Zee in the Physics Laboratory of Colorado Agricultural and Mechanical College during 1950 and 1951 under the joint direction of the other authors. By special arrangement the work was accepted for a dissertation leading to the degree of Ph.D. in irrigation engineering in 1952 by Utah State Agricultural College. Mr, Vaughn E. Hansen, Assistant Professor of Irrigation Engineering at the latter institution, directed the writing of the dissertation. Mr. W. E. Code, Irrigation Engineer, Colorado Agricultural Experiment Station and Mr. Peterson conducted the tests of the Mosca experimental well in 1954.

\section{LITERATURE CITED}

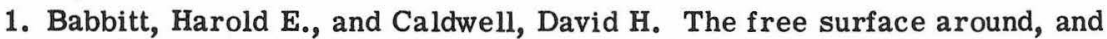
interference between, gravity wells. Bulletin series No. 374. Engineering Experimental Station, University of Illinois, Urbana, Illinois, 1948.

2. Hubbert, M. King. The theory of ground-water motion. Journal of Geology, 48:785-944, 1940.

3. Hansen, Vaughn E. Evaluation of unconfined flow to multiple wells by membrane analogy: (Ph. D. Thesis, Iowa State University) Iowa City, Iowa, 1949. Proc. ASCE, Separate No. 142, August, 1952.

4. Jacob, C. E. Drawdown test to determine effective radius of artesian well. Am. Soc. of Civil Eng. Trans. 112:1047-1070, 1947.

5. Taylor, D. W. Fundamentals of Soil Mechanics. New York, John Wiley and Sons, 1948.

6. Petersen, Jack Sterling. Effect of well screens on flow into wells. (Master's Thesis, Colorado A and M College), Fort Collins, Colorado, August, 1951.

7. Tolman, C. F. Ground Water. New York, McGraw-Hill Book Company, Inc., 1937. 
8. Wyckoff, R. D., Botset, H. G. and Muskat, M. Flow of liquids through porous media under the action of gravity. Physics, pp. 90-113, August, 1932.

9. Yang, Shih-Te. Seepage toward a well analyzed by the relaxation method. (Ph. D. Thesis, Harvard University) Cambridge, Mass., 1949.

10. Zee, Chong-Hung. The use of combined electrical and membrane analogies to investigate unconfined flow into wells. $(\mathrm{Ph} . \mathrm{D}$. Thesis, Utah State Agricultural College) Logan, Utah, 1952.

11. Wisler and Brater. Hydrology. New York, John Wiley and Sons, 1949.

\section{APPENDIX}

List of Symbols

E

$\mathrm{E}_{1}, \mathrm{E}_{2}$

$\mathrm{E}_{\alpha}, \mathrm{E}_{\mathrm{S}}, \mathrm{E}_{\mathrm{w}}$

$f_{1}, f_{2}, f_{3}$

h

$\mathrm{h}_{2}, \mathrm{~h}_{2}$

$\mathrm{h}_{\alpha}, \mathrm{h}_{\mathrm{s}}, \mathrm{h}_{\mathrm{w}}$

I

$\mathrm{I}_{\mathrm{T}}$

$\mathrm{I}_{\mathrm{w}}$

K

Q

$\mathrm{r}$

$\mathrm{r}_{1}, \mathrm{r}_{2}$

$r_{\mathrm{W}}$

$\mathrm{r}_{\alpha}$

$R_{1}, R_{2}, R_{3}, R_{4}$

$\mathrm{S}$
Electromotive potential or voltage.

Electromotive potential at points 1,2 in the field.

Electromotive potential at the tank boundary, at the outside of the well and at the well respectively.

A symbol designating a functional relationship.

Piezometric head at any point in the field, also the elevation of the free surface above the impermeable boundary. (L).*

Piezometric head at points 1,2 in the field; elevation of the free surface at points 1,2 in the field. (L).

Piezometric head or elevation of the free surface at the tank boundary, outside of the well and at the well respectively. (L).

Electrical discharge or current.

Electrical discharge through the electrolyte in the tank.

Electrical discharge through the well coil used to control the electrical potential at the simulated well.

The hydraulic permeability, sometimes designated the hydraulic conductivity. $\left(\mathrm{LT}^{-1}\right)$.

Total discharge of the hydraulic system $\left(\mathrm{L}^{3} \mathrm{~T}^{-1}\right)$

A radial co-ordinate measured from the well axis. (L).

Radial co-ordinates of points 1, 2. (L).

Radius of the well. (L).

Radius of the tank. (L).

Electrical resistances.

Model constant. Electromotive potential gradient in the direction $\mathrm{z}$ on a free surface.

* Where dimensional quantities are described, their dimensions are indicated by symbols as follows: L, length; $\mathrm{F}$, force; $\mathrm{T}$, time. 
Unit tension in the membrane. $\left(\mathrm{FL}^{-1}\right)$

Thickness of the membrane. (L).

y

Deflection of the membrane at a point. (L).

z

A vertical co-ordinate measured from the impermeable stratum. (L).

$\mathrm{z}_{1}, \mathrm{z}_{2}$

Vertical co-ordinates of points 1, 2. (L).

$\beta$

Angle of inclination of a streamline at the well boundary.

Unit weight. $\left(\mathrm{FL}^{-3}\right)$.

$\theta$

Co-ordinate angle.

Conductivity of an electrolyte. 


\title{
AMERICAN SOCIETY OF CIVIL ENGINEERS
}

\author{
OFFICERS FOR 1955 \\ PRESIDENT \\ WILLIAM ROY GLIDDEN \\ VICE.PRESIDENTS \\ Term expires October, 1955: \\ ENOCH R. NEEDLES \\ Term expires October, 1956: \\ MASON G. LOCKWOOD \\ FRANK L. WEAVER \\ LOUIS R. HOWSON
}

\section{DIRECTORS}

$\begin{array}{lll}\text { Term expires October, 1955: } & \text { Term expires October, 1956: } & \text { Term expires October, 1957: } \\ \text { CHARLES B. MOLINEAUX } & \text { WILLIAM S. LaLONDE, JR. } & \text { JEWELL M. GARRELTS } \\ \text { MERCEL J. SHELTON } & \text { OLIVER W. HARTWELL } & \text { FREDERICK H. PAULSON } \\ \text { A. A. K. BOOTH } & \text { THOMAS C. SHEDD } & \text { GEORGE S. RICHARDSON } \\ \text { CARL G. PAULSEN } & \text { SAMUEL B. MORRIS } & \text { DON M. CORBETT } \\ \text { LLOYD D. KNAPP } & \text { ERNEST W. CARLTON } & \text { GRAHAM P. WILLOUGHBY } \\ \text { GLENN W. HOLCOMB } & \text { RAYMOND F. DAWSON } & \text { LAWRENCE A. ELSENER } \\ \text { FRANCIS M. DAWSON } & \end{array}$

PAST.PRESIDENTS

Members of the Board

WALTER L. HUBER

DANIEL V. TERRELL

EXECUTIVE SECRETARY

WILLIAM H. WISELY
TREASURER

CHARLES E. TROUT

\section{ASSISTANT SECRETARY}

E. L. CHANDLER

\section{ASSISTANT TREASURER}

CARLTON S. PROCTOR

\section{PROCEEDINGS OF THE SOCIETY}

\author{
HAROLD T. LARSEN \\ Manager of Technical Publications
}

DEFOREST A. MATTESON, JR.

PAUL A. PARISI

Editor of Technical Publications

Assoc. Editor of Technical Publications

\author{
COMMITTEE ON PUBLICATIONS \\ SAMUEL B. MORRIS, Chairman \\ JEWELL M. GARRELTS, Vice-Chairman
}

